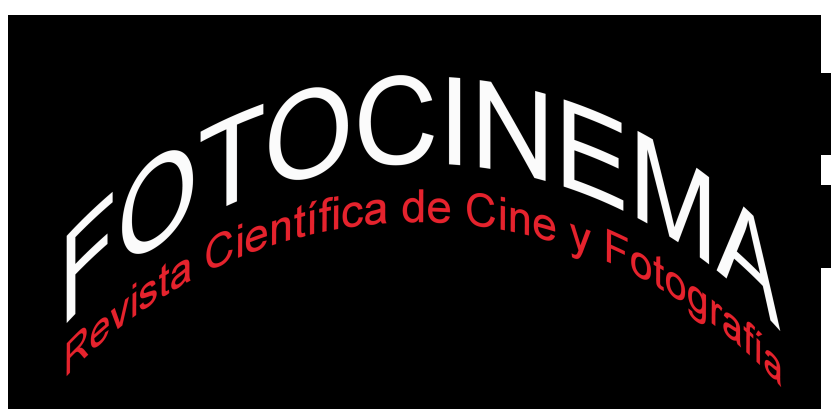

\title{
LOS PERSONAJES HOMOSEXUALES EN EL MELODRAMA CLÁSICO: ADAPTACIONES DE BROADWAY A HOLLYWOOD (1951- 1961)
}

\section{THE HOMOSEXUAL CHARACTERS IN THE CLASSIC MELODRAMA: ADAPTATIONS OF BROADWAY TO HOLLYWOOD (1951-1961)}

\author{
Valeriano Durán Manso \\ Universidad de Cádiz, España \\ valeriano.duran@uca.es
}

\section{Resumen:}

Los éxitos de Broadway han sido una de las principales fuentes de inspiración para Hollywood. En los años cuarenta, Tennessee Williams ocupó el espacio hegemónico de Eugene O'Neill, y sus potentes temas y personajes interesaron rápidamente a Hollywood. A principios de los cincuenta, el férreo Código Hays censuró varios aspectos sexuales de sus exitosas adaptaciones fílmicas, pero la presencia de personajes homosexuales resultó muy novedosa. Siguiendo esta tendencia, se adaptaron en estos años los dramas de Robert Anderson y de Lillian Hellman que los trataban. Con el objetivo de incidir en el impacto de los seres de ficción de esta orientación en Hollywood, se analizarán como persona y como rol -según Francesco Casetti y Federico di Chio-, los protagonistas de Té y simpatía (1956), La gata sobre el tejado de zinc (1958) y La calumnia (1961). Este trabajo intenta reflexionar sobre cómo los personajes de Anderson, Williams y Hellman, respectivamente, contribuyeron al aperturismo temático en Hollywood, a la fractura del Código Hays y a la evolución del melodrama clásico entre 1951 y 1961.

\begin{abstract}
:
The success of Broadway have been one of the main sources of inspiration for Hollywood. In the 1940s, Tennessee Williams took hegemonic space of Eugene O'Neill, so their powerful themes and characters interested quickly to Hollywood. At the beginning of the 1950s, the strict Hays Code censored some sexual aspects of their successful film adaptations, but the presence of homosexual characters was very novel. Following this trend, Robert Anderson and Lillian Hellman dramas that treated them were adapted in these years. With the aim to influence the impact of characters of this orientation in Hollywood, will be analysed as a person and as a role-according to Francesco Casetti and Federico di Chio, the protagonists of Tea and Sympathy (1956), Cat on a Hot Tin Roof (1958) and The Children Hour (1961). This work tries to reflect how the characters of Anderson, Williams and Hellman, respectively, contributed to openness theme in Hollywood, the Hays Code breaking and the evolution of the classic melodrama between 1951 and 1961 .
\end{abstract}

Palabras clave:

Personaje; homosexualidad; melodrama clásico; adaptaciones; Broadway; Hollywood.

Keywords:

Character; Homosexuality; Classic Melodrama; Adaptations; Broadway; Hollywood. 
Cómo citar: Durán Manso, V. (2018). Los personajes homosexuales en el melodrama clásico: adaptaciones de Broadway a Hollywood (1951-1961). Fotocinema. Revista científica de cine y fotografía, $\mathrm{n}^{\mathrm{0}}$ 16, pp. 307-334. Disponible: http://www.revistas.uma.es/index.php/fotocinema/ DOI: http://dx.doi.org/10.24310/Fotocinema.2017.voi16

\section{Introducción}

La estrecha relación entre el teatro y el cine tuvo una notable presencia en el periodo clásico de Hollywood (1927-1972); uno de los más decisivos en la evolución estilística del denominado séptimo arte. A este respecto, “podemos definir la narración clásica como una configuración específica de opciones normalizadas para representar la historia y para manipular las posibilidades de argumento y estilo" (Bordwell, 2009, p. 156). Tras su configuración como el espectáculo de masas más popular y el desarrollo de los géneros narrativos -como el melodrama, a partir de los años diez-, el cine de Estados Unidos inició una dilatada y bastante fructífera colaboración con el ámbito escénico de Broadway (Iglesias Simón, 2008). Por ello, durante el periodo silente se empezaron a adaptar los principales éxitos de los escritores europeos, debido al escaso desarrollo teatral norteamericano, y, en los años veinte, de Eugene O’Neill, el considerado "padre del teatro estadounidense” (Antón-Pacheco, 2005, p. 25). Así, la novela y el teatro se convirtieron en la principal fuente narrativa del cine (Sánchez Noriega, 2006), especialmente en Hollywood. En este marco, se gestaron las adaptaciones cinematográficas de las obras de los autores norteamericanos Lillian Hellman (Nueva Orleans, 1905-Oak Bluffs, Massachussetts, 1984), Tennessee Williams (Columbus, Mississippi, 1911Nueva York, 1983) y Robert Anderson (Nueva York, 1917-Nueva York, 2009); que fueron llevadas a la gran pantalla entre 1936 y 1968.

La aportación fílmica de estos dramaturgos está vinculada a sus innovaciones escénicas, como se puede percibir en el dramatismo de sus espacios y en la construcción de sus personajes. En este sentido, los años posteriores a la II 
Guerra Mundial estuvieron marcados en Hollywood por la crisis del sistema de estudios, el apogeo de la televisión y la caza de brujas del senador Joseph McCarthy (Durán Manso, 2016), mientras que Broadway mantenía su estatus entre la vanguardia y lo comercial. Esta situación propició que los éxitos más arriesgados de la escena neoyorquina fueran adaptados, y que los complejos seres de ficción de estos autores aparecieran ante un público más amplio. El cine de la década de los cincuenta destacó por el protagonismo de un nuevo tipo de personaje de marcado origen teatral, acusada profundidad psicológica y rupturista, incluso a nivel sexual. De esta manera, el estricto Código Hays creado en 1934 para proteger la moral de los espectadores (Black, 1998)-, se tuvo que enfrentar a los universos de Williams, Anderson y Hellman, en este orden, mientras advertía un progresivo debilitamiento. Así, entre los estrenos de la williamsiana Un tranvía llamado deseo (A Streetcar Named Desire, Elia Kazan, 1951) y La calumnia (The Children's Hour, William Wyler, 1961) -de Hellman-, esta fractura posibilitó un cierto aperturismo temático.

En este contexto, varios temas prohibidos por el código, como el adulterio, la violación, la homosexualidad, la ninfomanía o el alcoholismo, aparecieron en la pantalla por primera vez mediante estas adaptaciones. Con respecto a la representación de los seres de ficción homosexuales, en el Hollywood clásico sólo se podía sugerir esta orientación a través de diversos elementos visuales que de forma timorata favorecían su entendimiento, pues, desde su creación, el código catalogó la homosexualidad como una perversión y condenaba a las películas que la trataban (Durán Manso, 2016). Esto explica que la presencia de personajes de esta orientación fuera muy escasa desde 1934, y que hasta la década de los sesenta no se mostrara sin las restricciones de la censura. Así se constata que "el espectador cinematográfico ha aprendido a leer los textos visuales al mismo tiempo que se desarrollaban las formas de representación en las películas" (Balló, 200o, p. 15). En esta línea, destacan las aportaciones de estos dramaturgos al melodrama en una década en la que "casi adquirió la condición de género la densa corriente de adaptaciones literarias y escénicas de autores americanos de prestigio" (Gubern, 1996, p.73), como Francis Scott Fitzgerald, Arthur Miller, John Steinbeck o William Faulkner. 
Desde estas consideraciones, este trabajo pretende destacar la construcción de los personajes protagonistas homosexuales -masculinos y femeninos-, en algunas de las adaptaciones cinematográficas más representativas de la obra teatral de Tennessee Williams, Robert Anderson y Lilliam Hellman filmadas entre 1951 y 1961; unos años marcados por la lucha contra el Código Hays, el paulatino aperturismo temático y la evolución del melodrama clásico.

\section{Objetivos}

El objetivo general de este estudio es poner de manifiesto y reflexionar sobre la representación fílmica de los seres de ficción homosexuales y protagonistas de las obras de estos tres autores en un momento crítico para Hollywood. Así, se intenta constatar la evolución del tratamiento de este controvertido tema en la gran pantalla, en una época marcada por un férreo sistema de censura de carácter moralizante que lo prohibía desde los años treinta. De esta manera, se establecen los siguientes objetivos específicos:

- Definir el contexto teatral y fílmico norteamericano de las décadas de los cuarenta y cincuenta en el que se estrenaron algunas de las obras centrales de Lillian Hellman, Tennessee Williams y Robert Anderson.

- Destacar el proceso de adaptación cinematográfica de las tres obras de Anderson, Williams y Hellman que se abordan, Té y simpatía, La gata sobre el tejado de zinc y La calumnia, respectivamente.

- Analizar como persona y como rol a sus protagonistas homosexuales: Tom Robinson Lee (Té y simpatía), Brick Pollit (La gata sobre el tejado de zinc) y Karen Wright y Martha Dobie (La calumnia).

\section{Metodología}

Esta investigación es de carácter cualitativo-descriptivo. Para ello, en primer lugar, se ha procedido a la lectura de las citadas obras de estos dramaturgos, así como de publicaciones de autores sobre teatro norteamericano e historia del cine en Estados Unidos, como Antón-Pacheco (2004), Barton Palmer y 
Bray (2009), Black (1998), Gubern (1996), Iglesias Simón (2008), Pérez Rubio (2004) o Roberts (2003). Asimismo, se ha recurrido a publicaciones vinculadas a los estudios de género; en concreto, a la construcción y la representación de la masculinidad en el cine, además del tratamiento de la homosexualidad. Por este motivo, se han revisado obras de expertos en esta materia como Alfeo Álvarez (2007), Colina (2011), González de Garay (2017), Guarinos (2013), Melero (2014), Mira Nouselles (2011) o Zurián (2014). Por otra parte, han resultado muy pertinentes las aportaciones sobre el análisis del personaje audiovisual de investigadores como Bordwell (2009), Caminos (2006), Casetti y Di Chio (2007), Chatman (1990), Galán Fajardo (2007), Pérez Rufí (2016) o Sánchez Noriega (2006 y 2000).

En segundo lugar, se ha consultado material relativo a libros de cartas que recogen la correspondencia entre Tennessee Williams y Elia Kazan, y otras personas estrechamente ligadas al desarrollo de las obras y las adaptaciones cinematográficas de este dramaturgo. Además, se han revisado las memorias de Williams -por ser el escritor de este periodo con un mayor número de personajes homosexuales, tanto en el teatro como en el cine-, y las biografías de los realizadores Elia Kazan, Vincente Minnelli, Richard Brooks y William Wyler, responsables, en el primer caso, del montaje en Broadway de varias de las obras abordadas, y, en los tres últimos, de dirigir las adaptaciones de las mismas en la pantalla. En esta revisión bibliográfica han destacado textos de Comas (2004), Cuevas (2000), Devlin y Tischler (2004), Durán Manso (2016 y 2011), Kazan (1990), Torres (1995) o Williams (2008), entre otros.

En tercer lugar, para el análisis de personajes se ha procedido al visionado de las películas Té y simpatía (Tea and Sympathy, Vincente Minnelli, 1956), La gata sobre el tejado de zinc (Cat on a Hot Tin Roof, Richard Brooks, 1958) y La calumnia, protagonizadas por los cuatro seres de ficción que se estudian, respectivamente: Tom Robinson Lee, Brick Pollit, Karen Wright y Martha Dobie. Así, el análisis cuenta con dos personajes masculinos y dos femeninos, que intentan equilibrar el tratamiento de la homosexualidad en la pantalla a nivel de género. En cuanto al resultado final de estos personajes, es necesario señalar que el rostro, el físico y la interpretación de los actores que les dan 
vida -John Kerr, Paul Newman, Audrey Hepburn y Shirley MacLaine, en este orden-, están estrechamente conectados con su composición fílmica:

Por más que el autor lo describa con detalle, el personaje escrito es abstracto o, al menos, se ofrece al lector dejando a éste en libertad para ponerle rostro o concretarlo teniendo en cuenta su mundo particular. En cuanto dotado de la encarnadura del actor, el personaje cinematográfico siempre es la suma del actor y del personaje diseñado por el guión, porque los grandes actores (las estrellas en particular) son ellos mismos a lo largo de una filmografía variada con numerosos personajes. De ahí que la elección del actor es ya una primera aproximación a la construcción del personaje (Sánchez Noriega, 2006, p. 69).

A continuación, se ha aplicado en los protagonistas la plantilla de análisis de personajes creada en 2009 por el Grupo de Investigación en Análisis de Medios, Imágenes y Relatos Audiovisuales (ADMIRA), de la Universidad de Sevilla, basada en las aportaciones de Francesco Casetti y Federico di Chio. Esta herramienta cualitativa es heredera a su vez de destacados narratólogos, como Seymour Chatman, Algirdas Julius Greimas o Vladimir Propp, quien decía que "el personaje es como un hilo conductor que nos guía a lo largo de una estructura para reconocerla" (Caminos, 2007, p. 24), y distinguía "entre narraciones apsicológicas, centradas en la trama, y psicológicas, centradas en el personaje" (Sánchez Noriega, 2000, p. 126). Esta plantilla, que atiende a aspectos descriptivos y piscológicos, permite conocer la imagen, el habla, el carácter, las relaciones, el pensamiento, los sentimientos, la evolución, el nivel sociocultural, la sexualidad, o las acciones de los seres de ficción. No se puede obviar que "todo personaje viene definido por su ser (identidad, rasgos físicos, carácter, etc.) y por su hacer, por la conducta que desarrolla y por las relaciones que establece con otros personajes, lo que supone una serie de rasgos que lo individualizan" (Sánchez Noriega, 200o, p. 126). Además, al ser un personaje la suma de un significante y un significado, $y$, en este caso, ser homosexuales, "lo que interesa saber es, por un lado, qué rasgos constituyen el significante y hacia qué significados nos orienta su interpretación. Esto, que es evidente en cualquier construcción de personajes, es esencial en la construcción del personaje homosexual” (Alfeo Álvarez, 2007, p. 170). 
Estas adaptaciones son las primeras que se realizaron en Hollywood sobre las obras originales -a excepción de La calumnia, que tuvo una primera versión en 1936 -, y aunque han contado después con versiones televisivas en Estados Unidos y con montajes teatrales en varios países, no han vuelto a llevarse al cine. Se trata de adaptaciones integrales, es decir, que se mantienen fieles al original literario porque "el conjunto del texto teatral ha sido plasmado en el fílmico", de manera que "existe la voluntad de 'servir al texto', de plasmar en celuloide las cualidades dramáticas de la obra tal y como han sido expresadas por el autor" (Sánchez Noriega, 2000, p. 73). Al pertenecer al melodrama uno de los géneros más populares por su carácter emocional-, estas películas promueven el proceso de identificación entre el público y los protagonistas.

\section{Análisis}

\subsection{Contexto escénico y fílmico posterior a la II Guerra Mundial: dramaturgos, melodrama y homosexualidad}

Siguiendo la afirmación de Chatman (1990), "la narración evoca un mundo" (p. 128), de manera que buena parte de los sentimientos y las circunstancias de Tennessee Williams, Robert Anderson y Lilliam Hellman se plasmaron en sus personajes y, posteriormente, se exportaron a la escena y al celuloide. La libertad que caracterizaba a Broadway en la década de los cuarenta, donde los dramas de Eugene O’Neill empezaban a decaer y los de Hellman tenían el apoyo del público, acogió el espíritu rupturista de Williams. El autor sureño renovó la escena neoyorquina con su primera gran obra, El zoo de cristal, en 1945, una memory play en la que no ofrecía salida a unos protagonistas marcados por unas circunstancias desfavorables (Durán Manso, 2016). El texto, que sólo un año después se empezó a representar en París, Estocolmo, Roma y Atenas (Williams, 2008), dio paso a nuevas obras que ahondaban en la complejidad del ser humano y reflejaban el desencanto y la sordidez de la sociedad. En este contexto, y en esta línea, llegaron a Broadway dramaturgos nuevos, como Arthur Miller, William Inge y, ya en los cincuenta, Anderson (Roberts, 2003), cada uno con su propio universo psicológico. 
De origen judío, Lillian Hellman fue la primera mujer que llegó a Broadway en igualdad de condiciones que sus compañeros masculinos. A pesar de sus raíces sureñas, su obra no está estrictamente ligada al Old South, y tampoco presenta rasgos comunes a la de otros dramaturgos judíos estadounidenses (Antón-Pacheco, 2005). Su etapa universitaria en Nueva York y el traslado a Hollywood en 1925, afianzaron su ideología de izquierdas y su aproximación al cine. Debutó en el teatro en 1934 con The Children's Hour, que supuso su primer éxito al abordar el lesbianismo, la difamación y la represión moral en un internado femenino. Este insólito planteamiento no pudo plasmarse de forma fiel en el cine hasta 1961, pues, aunque ella escribió el guión, la versión de 1936 sufrió la censura. A este éxito siguieron Days to Come (1936), donde exhibió su postura política; La loba (The Little Foxes, 1939), donde ofrecía un certero retrato de la ambición humana que fue llevado al cine por Wyler en 1941; y Another Part of the Forest (1946), precuela de La loba que adaptó al celuloide Michael Gordon en 1948. Posteriormente, estrenó dos grandes obras: The Autumn Garden (1951), donde hizo un minucioso análisis de los personajes, y Toys in the Attic (1960), que trató la xenofobia, la represión y el incesto, y contó con una película dirigida en 1963 por George Roy Hill.

La intensidad de la dramaturgia de Hellman ocupó un lugar distinguido, pero no fue tan prolífica como la de Williams. Ambos compartían una gran unión con Nueva Orleans, ella de nacimiento y él de sentimiento, y una infancia en el sur que les otorgó una especial sensibilidad. Así se refleja en el segundo gran éxito de Williams, Un tranvía llamado deseo (1947), que fue el primero norteamericano en conseguir los tres premios principales: el Pulitzer, el New York Drama Critics' Circle Award y el Donaldson. La mixtura entre el espacio sureño asfixiante, la instrospección de los intérpretes del Actor's Studio y el tratamiento de temas como la violación, la ninfomanía o la homosexualidad, marcaron un hito en Broadway y, cuatro años después, en Hollywood (Kazan, 1990; Cuevas, 2000). Elia Kazan inició aquí sus colaboraciones con Williams:

Con Un tranvía llamado deseo, Kazan comienza a recorrer otros caminos, en los que la búsqueda del realismo adquiere un sesgo más psicologista. Ya no se trata de conseguir una apariencia externamente realista, sino de adentrarse en la realidad de unos personajes complejos. Para ello Kazan recrea un espacio 
físico abigarrado, que refuerza el confinamiento de los personajes y provoca su choque inevitable (Cuevas, 2000, p. 85).

La década de los cincuenta estuvo marcada por los estrenos de los dramas de Williams, que, además, se iban alternando con sus adaptaciones fílmicas. Así, a las películas El zoo de cristal (Irving Rapper, 1950) y Un tranvía llamado deseo (1951), siguieron La rosa tatuada (The Rose Tattoo, Daniel Mann, 1955), La gata sobre el tejado de zinc (1958), De repente... el último verano (Suddenly, Last Summer, Joseph L. Mankiewicz, 1959), Piel de serpiente (The Fugitive Kind, Sidney Lumet, 1960), Verano y humo (Summer and Smoke, Peter Glenville 1961) y Dulce pájaro de juventud (Sweet Bird of Youth, Richard Brooks, 1962), estrenadas previamente en Broadway en 1953, 1955, 1958, 1957, 1948 y 1959, respectivamente (Williams, 2008).

Por su parte, Robert Anderson tuvo ciertos problemas para que su primera obra, Té y simpatía, llegara a Broadway. Entre otros aspectos, era un autor novel y en ella trataba un tema tan espinoso como la homosexualidad en un internado (Cuevas, 2000). No obstante, Kazan, quien tenía experiencia en la dirección de los montajes de Williams, decidió enfrentarse al proyecto y lo convirtió en un éxito en 1953, de manera que su adaptación cinematográfica no tardó en filmarse (Roberts, 2003). Los contenidos de carácter sexual y la creación de unos personajes de interior complejo se convirtieron también en las señas de identidad de este autor. Así se constató en sus siguientes dramas, como All Summer Long (1954) y Silent Night, Lonely Night (1959), donde volvió a tratar el adulterio, aunque sin el éxito de su ópera prima.

Cuando se estrenaron la mayoría de las adaptaciones de estos autores, tras la II Guerra Mundial, Hollywood atravesaba un momento convulso. El sistema de estudios fue declarado un monopolio ilegal, el auge de la televisión causó una gran pérdida de espectadores y el pánico comunista incentivado por el senador McCarthy provocó una caza de brujas que acabó con las carreras de directores, guionistas y actores, generando una lista negra donde fue incluida Hellman (Black, 1998). A esto se sumó que el Tribunal Supremo estableció en 1952 que las películas estaban protegidas bajo la libertad de expresión que dictaba la Primera Enmienda de la Constitución de Estados Unidos. Con este 
marco, diversos cineastas apostaron por llevar al cine los éxitos de Broadway que abordaban aspectos controvertidos para la industria, pues mejorarían la taquilla. Así, la libertad de la escena neoyorquina se trasladó a Hollywood de forma gradual con los estrenos de estos títulos hasta los sesenta, debido a que el Código Hays prohibía la mayoría de los temas que abordaban, "poniendo a prueba el poder de esta organización” (Durán Manso, 2014, p. 28).

A pesar de su hegemonía, durante los años cincuenta el código sufrió diversas revisiones tras los estrenos de filmes que trataban aspectos que condenaba. En 1956 se anuló la prohibición referente a las drogas -tema central de $E l$ hombre del brazo de oro (The Man with the Golden Arm, Otto Preminger, 1955)-, el aborto, la prostitución y las relaciones interraciales, pues en 1954 la segregación racial había sido declarada inconstitucional (Gubern, 1996). Esto posibilitó que la homosexualidad se tratara de una forma más adulta, aunque con metáforas e indicaciones indirectas por el peso católico del código. No obstante, en 1961, tras el impacto de De repente... el último verano (1959) donde se abordaba claramente y sin mencionarla-, se realizó otra revisión a favor de esta sexualidad, así que acabó oficialmente la prohibición total que sufría desde 1933. Entre 1951 y 1961 aparecieron melodramas con personajes homosexuales principales -algo inédito en Hollywood-, aunque, debido a la censura, se acentuó la dimensión trágica de los mismos con la represión de su deseo, la marginación, la confusión derivada de su propia orientación o la muerte, mediante el asesinato o el suicidio. Pese a ello, el melodrama resultó el género más adecuado para expresar la complejidad psicológica de los seres de ficción, como se produce en las películas que centran este estudio.

\subsection{Adaptaciones: Anderson, Williams y Hellman en el cine}

\subsubsection{Té y simpatía:}

La obra llegó al Ethel Barrymore Theatre de Broadway el 30 de septiembre de 1953, con Elia Kazan como director y con Deborah Kerr y John Kerr en los roles de Laura Reynolds y de Tom Robinson Lee. Por este montaje Kazan obtuvo el prestigioso premio Donaldson, un galardón que en 1955 volvería a lograr por la dirección de La gata sobre el tejado de zinc. Robert Anderson 
intentó que este director la llevara a escena, y así ocurrió cuando éste finalizó en Broadway las representaciones de Camino Real, de Tennessee Williams (Kazan, 1990). Así lo recuerda el cineasta: "Me gustó; me pareció que era de dimensiones reducidas pero profunda en su contenido -y que reflejaba la realidad de Bob como hombre joven que era. [...] La obra había nacido de sentimientos verdaderos y estaba construida a la perfección” (Kazan, 1990: 563). Aunque durante la gira de prueba recibió críticas favorables, el autor y el director matizaron algunos aspectos antes de estrenar en Broadway, como humanizar a los personajes negativos: el marido de Laura y el padre de Tom. Anderson los reescribió para que se percibiera que intentaban, sin lograrlo, superar sus limitaciones; lo que les daba una mayor credibilidad y favorecía la conexión con el espectador a pesar de su posición antagonista.

La obra recibió una gran acogida de público y de crítica, y permaneció nueve meses en cartel en Broadway. A este respecto, Deborah Kerr destacó: "resultó algo más que un éxito. Fue un enorme impacto sociológico en el público. [...] Para mí, la pieza de Robert Anderson es una pequeña obra maestra” (Garci, 1996, p. 44). Asimismo, el director también ensalzó el montaje realizado: "no creo que la obra de Bob Anderson pudiera haberse producido mejor de como lo hicimos. Pero ese éxito no nos llovió del cielo; tuvimos que ir escogiendo los elementos uno tras otro para que encajaran", matizando que "sólo al final, cuando todo estuvo ensamblado, parecía muy simple”(Kazan, 1990, p. 562). Tras haber dirigido montajes de gran escala, como Un tranvía llamado deseo y Muerte de un viajante (Arthur Miller, 1949), a Kazan le cautivó la solidez y la sencillez que el drama presentaba: "Anderson's play is that of a miniaturist and he doesn't make one false step" (Ciment, 1988, p. 167).

$\mathrm{Al}$ convertirse en uno de los principales éxitos de Broadway, Metro Goldwyn Mayer compró los derechos y encargó la adaptación al productor Pandro S. Berman. Después de aceptar Vincente Minnelli la propuesta de dirigirla, le encargaron el guión de la película al propio autor. Sin embargo, este drama planteaba dos dificultades para aparecer en la gran pantalla, que, además, suponían el sostén de la historia: la homosexualidad y el adulterio. Como el Código Hays prohibía ambos temas, Anderson decidió, como solución, dejar 
la homosexualidad a un lado -aunque sí sugerirla-, y destacar otro aspecto clave: la persecución. Así, "resalta lo que tiene el original de acoso por un colectivo a un individuo por el único motivo de ser diferente. Y también la compasión, la piedad y el amor que llega a sentir una persona por otra en un momento de crisis" (Torres, 1995, p. 263). No obstante, el adulterio suponía un problema de difícil solución que no se podía disimular sin alterar el texto de forma notable. Por ello, el dramaturgo escribió un prólogo y un epílogo de tono moralizante para que la historia se contara mediante un flashback, y, además, planteó un final "con una carta donde la adúltera cuenta la ruptura de su matrimonio, el castigo recibido por su pecado" (Torres, 1995, p. 264).

El rodaje empezó a principios de 1956 con la misma pareja protagonista, así que Minnelli se limitó a seguir el guión y dirigir a unos actores que conocían bien la obra y los personajes. Curiosamente, y a pesar de la censura, consigió perfeccionar el original al incluir sus habituales planos secuencia, realizar un acertado empleo del CinemaScope y, en definitiva, contar lo mismo que en Broadway pero de una forma más sutil, e incluso efectiva. No obstante, desde la mirada actual, el filme "tiene insalvables problemas de censura y resulta demasiado teatral” (Torres, 1995, p. 50). Asimismo, la arriesgada apuesta del original por la homosexualidad quedó demasiado eclipsada en la pantalla por el tratamiento de un adulterio tan convencional como condenado; sin duda, la única estrategia posible para que la película se pudiera exhibir. Su estreno tuvo lugar el 27 de septiembre de 1956 en Nueva York. Sobre esta experiencia fílmica, Deborah Kerr declaró que “Anderson respetó el material cuanto pudo, pero el tema de la homosexualidad se suavizó bastante”, y que Minnelli aportó "su elegancia a una puesta en en escena realmente bella, muy cuidada, con unos colores meticulosamente seleccionados y que tenían mucho que ver -ésa fue su intención- con los personajes" (Garci, 1996, p. 44).

\subsubsection{La gata sobre el tejado de zinc}

La obra se estrenó en el Morosco Theatre de Broadway el 24 de marzo de 1955, con la dirección de Elia Kazan y con Ben Gazzara, Barbara Bel Geddes, Burl Ives, Mildred Dunnock, Pat Hingle y Madeleine Sherwood como Brick, Maggie, Big Daddy, Big Mama, Gooper y Mae Pollit, respectivamente. Como 
le había pasado con Un tranvía llamado deseo, Williams consiguió con esta obra los grandes premios de la dramaturgia: el Pulitzer, el New York Drama Critics' Circle Award y el Donaldson. Asimismo, Kazan volvió a enfrentarse a un nuevo montaje del autor, pero a éste no le convencían ni Bel Geddes - de quien opinaba que "she is a fine actress who has appeared in a number of hits on Broadway but I am not sure she is right for this part” (Devlin y Tischler, 2004, p. 561) -y, de hecho, prefería a Dorothy McGuire-, ni tampoco Ives porque era cantante (Kazan, 1990). El director confiaba en las posibilidades de la primera -quien ganó un Tony por el papel de Maggie-, y del segundo, a quien había dirigido en 1944 en el musical Sing Out, Sweet Land!, de Walter Kerr. No obstante, los problemas entre ambos no residían en el reparto, sino en aspectos relativos a la puesta en escena, como recuerda Kazan:

The difference between Williams and I had about the third act caused quite a stir in the annals of our theatre, emphasized by the publication of the text when the author published both the third act he preferred -one we didn't use. The author forgot that I offered twice to restore original third act -if he wished. But apparently he preferred the one he characterized as more 'commercial'. The play was a great success and again was well played by a comparatively unknown cast -not by great stars (Ciment, 1988, p. 167).

Debido al gran éxito que este montaje teatral obtuvo en Broadway, donde se representó en seiscientas noventa y cuatro ocasiones, Metro Goldwyn Mayer compró los derechos para adaptarlo al cine. Las tensiones familiares ante la próxima muerte del patriarca de los Pollit - una acaudalada familia del Delta del Mississippi-, la codicia en torno a la millonaria herencia, el alcohol como refugio ante la no aceptación de la propia orientación sexual, o la desilusión matrimonial, componían los principales ingredientes de una obra que, según el código, no podría llevarse a la gran pantalla. Sin embargo, el aspecto más problemático era la homosexualidad del protagonista, Brick, y sus continuos rechazos -y hasta asco-, a las propuestas íntimas de su mujer, Maggie, tras la muerte de su mejor amigo, Skipper, quien le confesó poco antes de morir que estaba enamorado de él (Durán Manso, 2016). Además, la ubicación de la trama en un espacio cerrado -una mansión sureña-, durante un sofocante día de verano, propiciaba el enfrentamiento de unos personajes al límite. 
Aunque George Cukor fue elegido como director, rechazó la oferta porque no le permitían abordar directamente la homosexualidad, de manera que, tras las negativas de Joshua Logan y de Joseph L. Mankiewicz, el proyecto recayó en Richard Brooks, quien estaba bajo contrato con el estudio. Modificar el contenido del filme sin mutilar la esencia del drama resultaba complicado, pero Brooks se enfrentó en 1958 a la adaptación con unos cambios sutiles que evitaron la condena por parte de la censura. A pesar del happy end que impuso el estudio, y que resultó demasiado esperanzador para la historia de Brick y Maggie al ofrecer una imagen positiva y salvadora de la institución matrimonial, este cineasta, que tenía una amplia trayectoria como guionista, logró mantenerse fiel al original. Así, sugirió la orientación de Brick para que los espectadores pudieran entender que tras su actitud ocultaba su tormento por no aceptar su homosexualidad; planteó su alcoholismo como una rápida salida ante su incapacidad de madurar a causa del fallecimiento de Skipper; y, por último, mostró el desdén hacia Maggie como respuesta a una supuesta infidelidad con el difunto. Por otra parte, Brooks coincidía con los cambios aportados por Kazan en el tercer acto, como la reacción final de Brick, pues no concebía que no pudiera superar su depresión (Kazan, 1990).

El rodaje se desarrolló con algunos de los intérpretes originales, como Burl Ives y Madeleine Sherwood, y con las incorporaciones de Judith Anderson como Big Mama, Jack Carson como Gooper y, sobre todo, Paul Newman y Elizabeth Taylor como Brick y Maggie, quienes dieron una gran credibilidad a los protagonistas. Esta película sobre la terrible verdad humana (Devlin y Tischler, 2004), que se estrenó en Nueva York el 18 de septiembre de 1958, tuvo tanto éxito como el drama en Broadway, y así lo demostraron sus seis nominaciones a los Oscar, entre otros premios. Además, destacó por tener al primer protagonista homosexual de Hollywood (Durán Manso, 2016).

\subsubsection{La calumnia}

La obra llegó al Maxine Elliott Theatre de Broadway el 20 de noviembre de 1934, bajo la dirección de Herman Schumlin y con Katherine Emery, Anne Revere y Robert Keith en los roles de Karen Wright, Martha Dobie y Joseph Cardin, respectivamente. La complejidad psicológica de estos personajes y la 
apuesta por un tema tan inédito como la homosexualidad femenina, fueron las cartas de presentación de la ópera prima de Lillian Hellman. Asimismo, suponía una crítica al puritanismo social, que cautivó al público y a la crítica, y contó con seiscientas noventa y una representaciones en Broadway que se extendieron hasta julio de 1936. Con tales ingredientes, el productor Samuel Goldwyn compró los derechos para el cine con unas condiciones bastante particulares que se repetirían en muchas adaptaciones del Hollywood clásico: llevar a la gran pantalla éxitos de Broadway pero sin sus contenidos sexuales. Así, “obligado por la oficina Hays, Goldwyn no podía utilizar el título original ni publicitarlo con la película, ni tampoco decir públicamente que había comprado la obra. Y además sabía que no le aceptarían nunca el lesbianismo, directo o sugerido, de las dos protagonistas" (Comas, 2004, p. 82).

William Wyler fue el encargado de dirigir la adaptación cinematográfica, que llevó por título Esos tres (These Three, 1936), y, para ello, Hellman adaptó su propia obra -que estaba inspirada en un hecho real ocurrido en Escocia en 1810-, para ambientarla en la Nueva Inglaterra de los años treinta (Comas, 2004). Como no podía evitar el código -que acababa de instaurarse y tenía mucha fuerza-, Wyler accedió al consejo de la autora de filmar la verdadera esencia de la obra: el daño que puede provocar una calumnia. La película no pudo ser fiel al original, y sus protagonistas, encarnados por Merle Oberon, Miriam Hopkins y Joel McCrea, se vieron atrapados en un triángulo amoroso heterosexual en el que la figura central ya no era Karen, sino Joe. Además, el trágico desenlace con el suicidio de Martha fue sustituido por un happy end que la condenaba a la soledad y favorecía la unión de Karen y Joe; sin duda, un castigo a la homosexualidad. Empero, se mantuvieron aspectos originales, como la crítica a una sociedad provinciana y destructiva, y la devastación de la calumnia en los personajes. El estreno tuvo lugar el 18 de marzo de 1936 en Nueva York, cuando las representaciones seguían en Broadway.

La nueva situación de la industria cinematográfica en los sesenta permitió que este drama se pudiera llevar al cine como fue concebido por Hellman. Así, Wyler decidió hacer un remake de Esos tres en 1961, "convencido de que en su momento se había sentido demasiado presionado por Samuel Goldwyn y deseaba hacerla de nuevo tal como le hubiese gustado a la autora" (Comas, 
2004, p. 248). Debido a la crisis del código, varios filmes habían tratado la homosexualidad recientemente de forma sugerida para que los espectadores entendieran lo que sucedía sin verlo. Sin embargo, La calumnia mostraría sin tapujos el lesbianismo del original y sería el primer filme en enfrentarse a este tema abiertamente. Hellman elaboró el guión de esta nueva versión con el guionista John Michael Hayes, y pudo exponer claramente los elementos sexuales del drama, como el deseo de Martha hacia Karen, la declaración de la propia orientación -en el caso de Martha-, y la confusión ante la misma en el de Karen-, además del suicidio final (Balmori, 2009), la hipocresía y la intolerancia, en el marco de un elitista internado femenino.

La adaptación, que estuvo de nuevo bajo el sello de United Artists y recuperó el título original, reunió a Audrey Hepburn, Shirley McLaine y James Garner en los papeles de Karen, Martha y Joe. Se trataba de la primera vez que dos estrellas de Hollywood interpretaban a dos lesbianas, aunque, como ocurría en la obra, la palabra lesbianismo no se menciona en la película. En cuanto a la dirección de estas actrices, que hasta entonces habían protagonizado más comedias que dramas, destacó el matiz psicológico de sus interpretaciones. Para ello, Wyler contrapuso "la dulzura de Audrey y la fragilidad de Shirley con el tono dramático de las situaciones. Va tranquilizando al espectador con esta suavidad y le desconcierta con golpes dramáticos inesperados" (Comas, 2004, p. 251), una táctica narrativa que se intensifica en el suicidio. Con el objetivo de optar a los Oscar, el filme se estrenó en Estados Unidos de forma restringida el 19 de diciembre de 1961, y de modo abierto el 15 de marzo de 1962. Aunque resultó fiel al original, la crítica y la taquilla fueron desiguales, pues se esperaba que fuera aún más explícita con el aspecto homosexual. No obstante, recibió cinco nominaciones a estos premios; un claro indicador de la superación de las restricciones del código sobre este tema.

\subsection{Análisis de personajes}

\subsubsection{Tom Robinson Lee: un adolescente marginado}

Té y simpatía se desarrolla en un colegio universitario masculino de Nueva Inglaterra, próximo al mar. La acción comienza diez años después de que el 
protagonista, Tom Robinson Lee, tuviera que dejarlo tras intentar suicidarse debido al trato vejatorio que sufría por parte de sus compañeros. Con motivo de un encuentro de antiguos alumnos, Tom vuelve, y, desde la habitación que ocupó, recuerda sus últimos días en un centro educativo donde sólo encontró la comprensión de la mujer del director, Laura Reynolds.

El protagonista es un chico de 18 años, alto, de aspecto frágil, cabellos rubios y formas delicadas, que se manifiestan tanto en su forma de caminar como en sus gestos y gustos. No obstante, su elegante apariencia lo sitúa en el punto de mira de sus rudos y viriles compañeros. Así se refleja en su indumentaria, a pesar de que suele vestir como los demás chicos, es decir, con ropa formal para asistir a clase y a actos académicos, y con una sudadera y pantalón corto para las actividades deportivas. En cuanto a su forma de hablar, emplea un discurso elaborado y un tono educado, incluso ante quienes le agreden. Su principal transformación iconográfica se produce cuando su habla se torna violenta al no poder evitar que los demás lo consideren homosexual.

A nivel psicológico, Tom tiene un carácter introvertido y solitario. Su correcto comportamiento despierta recelos entre los personajes masculinos por estar alejado de la vida estudiantil en un entorno masculinizante. Esto afecta a su relación con ellos, pues "incluso su padre y su tutor le afean constantemente su conducta 'afeminada"' (Pérez Rubio, 2004, p. 163). Así, el recto Herb Lee se queda atónito al conocer que han visto a su hijo en la playa cosiendo y que lo llaman 'damisela', pero, aunque le exhibe su rechazo, "el defecto del padre no era que quisiera hacer daño a su hijo, sino que no tenía capacidad para comprenderlo" (Kazan, 1990, p. 564). El único que muesta compasión por él es su compañero de habitación, Ralph, quien lo defiende y "trata de ayudarle enseñándole a andar de una manera más viril, pero no tiene más remedio que decirle que su padre le ha ordenado cambiarse de habitación" (Torres, 1995, p. 261). Tom, que no tiene madre, entabla con Laura un vínculo donde ella le brinda protección, así que "el héroe -o tal vez el antihéroe- fracasado, o simplemente herido, busca en la mujer maternal y divinizada el consuelo que no encuentra en su vida normal” (Balló, 2000, p. 53). El joven cultiva un 
pensamiento romántico repleto de poesía y otras artes, y en sus sentimientos prima la sensibilidad. Por ello, cede a los deseos amorosos de Laura:

El filme presenta dos personajes heridos, Tom y Laura, dos almas gemelas que tienen que habitar en un entorno social intransigente, tribal, lleno de tabúes. Pero Laura conseguirá sobrevivir con mayor dignidad porque su sensibilidad está en consonancia con el papel de mujer y abnegada esposa que la sociedad le asigna, y Tom padece su condición de diferente respecto a los varones heterosexuales dominantes (Pérez Rubio, 2004, p. 164).

La incomprensión condiciona su evolución vital. El momento más grave se produce cuando intenta suicidarse con un cuchillo tras visitar a la prostituta Ellie Martin -con el fin de demostrar su hombría-, pues el encuentro resulta un desastre y ella se ríe de él al percibir que no es heterosexual. Aunque Tom se hunde, justo después se produce un hecho inesperado: Laura, movida por el dolor que le produce verlo, lo seduce y se acuesta con él "para demostrarle que es normal” (Torres, 1995, p. 262). Debido a la estructura circular de la película, aparece al final como un prestigioso escritor, y casado, al que la vida ha beneficiado tras una juventud marcada por continuas humillaciones.

Tom tiene un nivel socioeconómico elevado debido al estatus de su padre, y, en el momento en el que comienza la acción, a su carrera literaria, pues acaba de publicar un exitoso libro sobre su colegio. Además, posee un nivel cultural alto por las inquietudes literarias y artísticas que ostenta, como se proyecta en las conversaciones que mantiene con Laura. En cuanto a su orientación, es homosexual, pero no vive esta condición con naturalidad al encontrarse atrapado en un entorno homófobo, y, además, tampoco se acepta. Respecto al análisis como rol, el protagonista desempeña el de fugitivo, pues se halla en continua huida de sí mismo y se siente perdido en una sociedad hermética que lo juzga duramente porque no se ajusta al patrón convencional.

\subsubsection{Brick Pollit: un antihéroe atrapado}

La gata sobre el tejado de zinc se desarrolla durante la fiesta del sesenta y cinco cumpleaños de Big Daddy Pollit, un millonario hacendado sureño que ignora que sufre un cáncer terminal. El protagonista, Brick Pollit, se desplaza hasta la casa familiar de Mississippi junto a su mujer, Maggie, aunque sufre 
una profunda depresión y vive refugiado en el alcohol tras la reciente muerte de su mejor amigo, Skipper. Esta cita familiar propicia el descubrimiento del verdadero problema de Brick: su inconfesable homosexualidad.

En cuanto al análisis del personaje como persona, a nivel iconográfico Brick tiene 30 años y un atractivo aspecto físico que destaca por su rostro juvenil, sus ojos azules y su atlética figura, heredera de su pasado deportivo. Aunque al principio aparece con traje, camisa y corbata, pasa casi todo el tiempo con un pijama gris por el reposo que tiene que guardar tras romperse el tobillo en la escena inicial. Su habla posee un discurso parco en palabras y un tono de voz hiriente, sobre todo con su mujer y con su padre. Él sufre una notable transformación en la parte final que se percibe en su vestuario, al ponerse un pantalón de pana que oculta la escayola y una camisa blanca que denota la sinceridad a la que se enfrentará, y en una alocución sosegada con los suyos.

A nivel psicológico, Brick posee un carácter débil y una conducta que fluctúa entre la impasibilidad y la agresividad debido a su depresión. Aunque parece tener todo para ser feliz -juventud, dinero y amor-, está en un pozo que lo ha llevado al alcohol. Él reúne las razones por las que alguien cae en la bebida, que señala Williams: "Why does a man drink: in quotes "drink". There's two reasons, separate or together. 1. He's scared shitless of something. 2. He can't face the truth about something" (Devlin y Tischler, 2004, p. 555). Así, el vaso de whisky, la muleta, la escayola y el pijama son los indicadores de su estado anímico -a nivel físico y psicológico-, pues "los motivos visuales nos hablan del argumento" (Balló, 2000, p. 13), y de los personajes. Esta situación afecta notablemente a la forma en que se relaciona con su entorno, pues se muestra implacable con quienes más le importan -su esposa y su padre-, y dejado con su hermano, su cuñada y su madre. A este respecto, su vínculo con Maggie está muy deteriorado tras el suicidio de Skipper, pues la acusa de seducirlo antes de morir, y desde entonces se niega a que tengan relaciones, a pesar de los intentos fallidos de ella. Su relación con Big Daddy es el resultado de años de falta de cariño e incomprensión por ambas partes, aunque su progenitor desea que afronte sus problemas e intuye que la clave es Skipper. 
Brick posee un pensamiento íntegro -aunque es injusto con Maggie-, y odia la mendaciadad a pesar de estar instalado en ella (Durán Manso, 2011). Esta dicotomía aparece también en sus sentimientos, atrapados entre su amor por Maggie y la mezcla de duelo, dolor, pasión y deseo que siente por Skipper. La aceptación de su culpa sobre la tragedia de este chico y su acercamiento a Big Daddy marcan su evolución personal. El patriarca le habla sin tapujos de su amigo, y Brick, abatido, insinúa que antes de que se suicidara, lo despreció al confesarle sus sentimientos por él. Sin embargo, a continuación reacciona de forma violenta y le dice a Big Daddy que va a morir. Enfrentarse a la verdad supone un acto purificador para Brick, y así se refleja cuando se reconcilia con su padre y apuesta por un futuro con Maggie mediante la búsqueda de un hijo que simboliza la ruptura con el pasado (Barton Palmer y Bray, 2009).

Brick posee un nivel socioeconómico y cultural alto por su carrera deportiva y la fortuna agrícola de su padre, pero es un joven muy sencillo. En lo referente al aspecto sexual, es homosexual, pero no descubre su verdadera orientación hasta que muere Skipper. Además, empieza a plantearse que ambos estaban enamorados y esto lo perturba: "Brick tiene miedo de reconocerse a sí mismo pues en su mente no cabe otro comportamiento que no sea el heterosexual y, además, su posición social se lo impide” (Durán Manso, 2011, p. 53). Por otra parte, en cuanto al análisis como rol, desempeña el de alma a la deriva, pues no tiene ningún aliciente debido a la grave depresión que atraviesa, y es su padre, a las puertas de la muerte, quien favorece su recuperación.

\subsubsection{Karen Wright y Martha Dobie: dos víctimas de la sociedad}

La calumnia transcurre en un selecto internado femenino dirigido por las jóvenes profesoras Karen Wright y Martha Dobie. La armonía imperante en el colegio se trunca por completo cuando una alumna, Mary Tilford, difunde una calumnia contra las docentes como venganza por haber sido castigada. La acusación de que ambas mantienen una relación sentimental escandaliza a la elitista y puritana sociedad de Nueva Inglaterra, y provoca devastadoras consecuencias, profesionales y personales, en las protagonistas.

En lo referente al análisis del personaje como persona, a nivel iconográfico Karen tiene sobre 30 años, es alta, estilizada y posee un agraciado rostro en el 
que sobresalen sus grandes ojos oscuros y su amplia sonrisa. Este atractivo físico se ensalza con su distinguido aspecto, como denotan el sobrio vestuario que suele portar - para trabajar en un centro educativo como el que dirige-, y sus delicados modales. Asimismo, su forma de hablar se caracteriza por el uso de un amplio vocabulario y un tono de voz amable y cercano, que nunca eleva. La principal transformación que experimenta está relacionada con este aspecto, y así se produce cuando no puede desmentir la calumnia.

A nivel psicológico, posee un carácer afable que se manifiesta en su amable y educado comportamiento. Así se refleja en sus relaciones con las personas de su entorno directo, como Martha y Joe, su novio. Con la primera, mantiene una relación profesional donde existe un notable componente emocional y afectivo, pues ambas crearon y regentan el colegio debido a la amistad que les une. Se puede decir que Martha no sólo es una compañera para ella, sino una confidente con quien comparte una parte esencial de su vida: el amor por la docencia. Con Joe, que es médico y trabaja en un hospital, está a punto de casarse, pero suelen discutir por la intensa dedicación laboral de Karen. A su vez, el enlace supondrá su alejamiento del colegio, y esta idea la enfrenta con Martha porque la necesita en el centro. Por otra parte, actúa con autoridad y dulzura con las alumnas, a las que imparte asignaturas como música, francés u orientación. Además, guarda una relación cordial con Mary, incluso cuando difunde el rumor, aunque es "un personaje odioso, lleno de rencor y deseos de venganza, una chica malcriada de la alta sociedad capaz de cualquier cosa para conseguir sus caprichos" (Comas, 2004, p. 83).

La maestra tiene un pensamiento íntegro, como se advierte en su forma de educar a las niñas y en su mesura ante los trágicos hechos que se producen. Esto va ligado a sus sentimientos nobles y profundos, y así lo expresa en el amor que siente por Joe, la amistad que tiene con Martha y la satisfacción que le reporta su labor como profesora (Durán Manso, 2014). La calumnia lanzada por Mary marca violentamente su evolución psicológica. Esta chica difunde que sus maestras son lesbianas tras dos conversaciones que oye por separado: la primera, sobre el retraso de la boda de Karen por la insistencia de Martha de no quedarse sola al frente del colegio, y la segunda, cuando Lily 
habla de la obsesión de su sobrina Martha con Karen. Rápidamente, todas las niñas transmiten la situación a sus familiares, quienes las sacan de allí, "por la sospecha de un entendimiento sexual desviado que se percibe como una amenaza y un insulto al equilibrio social” (Loscertales y Núñez, 2001, p. 102). Esto supone el cierre del internado, un juicio por difamación que las docentes pierden, la ruptura entre Joe y Karen -quien rompe con él porque sabe que nada podrá ser igual entre ellos-, y el sucidio de Martha.

Este personaje tiene un nivel cultural alto por su formación y su ocupación, y un nivel socioeconómico medio porque es una trabajadora. En cuanto a su sexualidad, Karen parece heterosexual, pero tras su ruptura y la confesión de Martha, se plantea irse juntas a otra ciudad para empezar de nuevo. Por ello, se intuye que ignoraba su verdadera orientación. En cuanto al análisis como rol, ejerce el de fugitiva -a nivel psicológico y físico-, pues hasta que no se lanza el rumor, no se descubre a sí misma. Así, "la escena final en el funeral de Martha muestra a una Karen que, después de unos titubeos, vence su tristeza y va adquiriendo confianza despreciando a la sociedad que le rodea, disponiéndose a afrontar un futuro en total libertad" (Comas, 2004, p. 252).

En lo que respecta al análisis de Martha como persona, a nivel iconográfico se puede apuntar que tiene unos 30 años, es más baja que Karen, posee un rostro agraciado -aunque siempre presenta un gesto serio-, es rubia y lleva el pelo corto. A diferencia de la anterior, su vestuario es sencillo y sus modales suelen resultar bruscos, de manera que proyecta una imagen poco cuidada. Esto se verifica en su forma de hablar, pues es parca en palabras, no muestra cercanía y su tono a veces es cortante. La principal transformación que sufre se produce en su habla, al conseguir confesar sus sentimientos a Karen.

A nivel psicológico, tiene un carácter impulsivo que se refleja en su decidido e irritable comportamiento, pero es tímida e introvertida. Esta actitud esconde a una chica sensible que se ha construido una coraza para evitar que le hagan daño (Durán Manso, 2014). Martha se dedica a la administración y gestión del colegio, y esto ha marcado la distante relación que tiene con las alumnas. Sin embargo, a Mary le profesa una profunda antipatía que, en realidad, es mutua. Karen es la persona con quien mantiene un vínculo más estrecho, 
pues es su amiga, su socia, y su amor, aunque lleva años disimulándolo. Por ello, no le agrada que se quiera casar con Joe, y tiene con él un trato que se limita a la cordialidad. Así, resulta un personaje más atormentado que en la versión de 1936 -donde se limitaba a ser la amiga de la pareja y su realidad quedaba camuflada por una cuestión social-, como se refleja en su dicotomía personal. Su despistada tía Lily, quien la ayuda en las tareas del colegio, es la única que imagina el origen de sus problemas, pero Martha guarda siempre las distancias con ella y la trata con desdén cuando la critica.

En cuanto a su pensamiento, la joven es responsable y estricta en su trabajo, pero posee un mundo interno tan contradictorio que no puede ser feliz. Esto se advierte especialmente en sus sentimientos, pues carece de pareja, teme reconocer lo que siente por Karen, no se acepta a sí misma, y es consciente de que la sociedad la rechazaría y perdería a su compañera si la descubrieran. Por este motivo, cuando Mary difunde que es lesbiana y todos dan la espalda a las maestras -incluso Joe-, se atreve a exponerle a Karen todo lo que siente por ella. Esta declaración responde a la evolución psicológica tan relevante que experimenta, pues si la difamación no se hubiera producido, nunca se habría atrevido a revelar sus verdaderos sentimientos. No osbtante, y aunque Karen no la rechaza, Martha se halla en un callejón donde sólo encuentra el suicidio como salida. De esta manera, se ahorca -mientras que en la obra se pegaba un tiro-, a pesar de que poco después la abuela de Mary, Amelia, va al colegio para decirle que en realidad su nieta difundió una calumnia.

Este personaje posee un nivel cultural alto por su formación y su trabajo en un selecto centro educativo, y un nivel socioeconómico medio. En el ámbito sexual, Martha es lesbiana, y así lo indican que nunca haya tenido novio, que todas sus atenciones sean para Karen, que no le resulte simpático el novio de ésta, que quiera librarse de su tía Lily -quien asegura que está obsesionada con su amiga-, y que no se acepte. A diferencia de Karen, siempre supo que era homosexual, pero, aunque estaba enamorada de la docente, esta realidad la atormentaba. En cuanto al análisis como rol, desempeña el de alma a la deriva al ser incapaz de salir de un conflicto interno que la acompaña desde siempre. Así, motivada por huir de una situación insoportable, pone fin a su 
vida; una trágica decisión que enfatiza el poderoso y devastador papel de la sociedad en algo tan íntimo como es la sexualidad de cada individuo.

\section{Reflexiones finales}

Las adaptaciones cinematográficas de las principales obras de dramaturgos como Lillian Hellman, Tennessee Williams y Robert Anderson destacan por la intensidad de los temas que abordan, el dramatismo de los espacios que plantean y el carácter atormentado de sus personajes. Estos filmes tuvieron una relevante repercusión en las décadas de los cincuenta y sesenta porque se estrenaron durante la crisis estructural, política y económica que atravesaba Hollywood; apostaban por aspectos que prohibía el Código Hays; y, en varios casos, presentaban unos protagonistas homosexuales inéditos al combinar atractivo físico y una gran complejidad interna. No obstante, las alteraciones censoras que sufrieron no las modificó significativamente, y esto propició la evolución de Hollywood hacia planteamientos temáticos más maduros.

Estos escritores apostaron por un tipo de personaje poco habitual que tuvo en la gran pantalla un mayor impacto que sobre las tablas. En la mayoría de los casos, se trata de jóvenes de buen aspecto y alto nivel cultural y educativo, que están atrapados en su propia sexualidad al no aceptarla. Los masculinos homosexuales son en esta etapa más numerosos que los femeninos, y suelen ser víctimas de sí mismos, mostrarse débiles y vivir en entornos hostiles. Sin embargo, suelen tener cerca personajes compasivos que les ayudan, muchos femeninos, que se erigen como representaciones modernas de La Piedad (Balló, 1997). Su complejo mundo indica que "una teoría del personaje viable debería conservarse abierta y tratar a los personajes como seres autónomos y no como simples funciones de la trama" (Chatman, 1990, p. 128).

A este respecto, Tom Robinson, Brick Pollit, Karen Wright y Martha Dobie poseen una naturaleza repleta de matices y experimentan una inesperada y notable evolución psicológica. Además, representan distintas imágenes de la homosexualidad: la adolescencia, el matrimonio y la amistad, en este orden; tres ámbitos donde su plasmación en el cine adquiere un vital protagonismo al tratarse de esferas de la vida privada. Las instituciones educativas juegan 
un importante papel en la representación de esta orientación, como se revela en dos de las tres películas tratadas: Té y simpatía y La calumnia. En ellas se muestra en conflicto con la sociedad, prejuzgada, incomprendida y rechazada por la mayoría de los estudiantes, docentes y familiares. Asimismo, el filme de Minnelli y La gata sobre el tejado de zinc presentan el conflicto existente entre la masculinidad hegemónica y cualquier otra que no siga sus reglas, y así se manifiesta especialmente en las relaciones paternofiliales: la del joven Tom y Herb Lee, y la de Brick y Big Daddy, respectivamente.

La apuesta por temas que condenaba el Código Hays resultaba necesaria en estos años de crisis en el cine clásico. Por ello, y aunque de forma sugerida, la presencia de la homosexualidad indicó un tímido aperturismo en Hollywood. Así se percibe en el tratamiento de los personajes de esta orientación en estos melodramas, que va desde la perversión y la tragedia iniciales a un carácter más psicológico. Empero, la visión negativa de esta sexualidad se mantiene en los tres casos debido al puritanismo y conservadurismo americano.

\section{Referencias}

Alfeo Álvarez, J. C. (2007). Una propuesta cuantitativo/cualitativa de análisis del personaje cinematografico aplicada al personaje homosexual. En Marzal Felici, J. Gómez Tarín, F. J. (eds.) Metodologías de análisis del film. Madrid: Edipo, pp. 167-178.

Antón-Pacheco. A. (2005). El teatro de los Estados Unidos. Historia y crítica. Madrid: Langre Biblioteca Paralela.

Berman, P. S. (productor) \& Minnelli, M. (director) (1956). Té y simpatía [Cinta cinematográfica]. E.E.U.U: Metro Goldwyn Mayer.

Balló, J. (2000). Imágenes del silencio. Los motivos visuales en el cine. Barcelona: Editorial Anagrama.

Balló, J. y Pérez, X. (1997). La semilla inmortal. Los argumentos universales en el cine. Barcelona: Editorial Anagrama.

Balmori, G. (2009). El melodrama. Madrid: Notorious ediciones.

Barton Palmer, R. \& Bray, R. (2009). Hollywood's Tennessee. The Williams Films and Postwar America. Austin: University of Texas Press.

Black, Gregory D. (1998). Hollywood censurado. Madrid: Cambridge University Press. 
Bordwell, D. (2009). La narración en el cine de ficción. Barcelona: Ediciones Paidós Ibérica.

Caminos, A. (2007). La construcción de personajes. Perspectiva general. En Sangro Colón, P. y Huerta Floriano, M. A. (eds.) El personaje en el cine. Del papel a la pantalla. Madrid: Ediciones Calamar, pp. 21-49.

Casetti, F. y Di Chio, F. (2007). Cómo analizar un film. Barcelona: Ediciones Paidós.

Chatman, S. (1990). Historia y discurso. La estructura narrativa en la novela y en el cine. Madrid: Taurus Humanidades.

Comas, A. (2004). William Wyler. Su obra. Su época. Madrid: T\&B Editores.

Ciment, M. (1988). Elia Kazan. An American Odisey. London: Bloomsbury Publishing.

Colina, C. (coord.). (2011). Arcoúris mediático. Comunicación, género y disidencia sexual. Madrid: Ediciones Fragua.

Cuevas, E. (2000). Elia Kazan. Madrid: Ediciones Cátedra. Signo e Imagen/ Cineastas.

Devlin, A. J. \& Tischler, N. M. (2004). The Selected Letters of Tennessee Williams. Volume II. 1945-1957. New York: New Directions Publishing Corporation.

Durán Manso, V. (2016): La representación del deseo en el cine de Tennessee Williams: homosexualidad masculina frente al Código Hays. FEMERIS. Revista Multidisciplinar de Estudios de Género, Vol. 1, Nos. 1-2, pp. 58-73. Recuperado de http://erevistas.uc3m.es/index.php/FEMERIS/article/view/3227/1912

Durán Manso, V. (2014): El aula rompe con la censura en Hollywood: el caso de La calumnia. En: Comas Rubí, F.; González Gómez, S.; Motilla Salas, X. y Sureda García, B. (Edits.): Imatges de l'escola, imatge de l'educació. Palma de Mallorca: Edicions Universitat de les Illes Balears, pp. 19-37.

Durán Manso, V. (2011). La complejidad psicológica de los personajes de Tennessee Williams. FRAME, No 7, pp. 38-76. Recuperado de http://fama2.us.es/fco/frame/frame7/estudios/1.3.pdf

Galán Fajardo, E. (2007): Fundamentos básicos en la construcción del personaje para medios audiovisuales. Revista del CES Felipe II, No 7 . Recuperado http://www.cesfelipesegundo.com/revista/numeros.html

Garci, J. L. (1996). Conversaciones con Deborah Kerr (y II). Una por una... Deborah comenta su filmografía con José Luis Garci. Nickel Odeón. Revista trimestral de cine. Madrid, 2, pp. 27-62.

González de Garay, B. y Alfeo, J. C. (2017). Formas de representación de la homosexualidad en el cine y la televisión españoles durante el franquismo. L'Atalante: revista de estudios cinematográficos, $\mathrm{N}^{\circ} 23$, pp. 
http://www.revistaatalante.com/index.php?journal=atalante\&page $=\mathrm{a}$ rticle\&op $=$ view\&path $\% 5 \mathrm{~B} \% 5 \mathrm{D}=386 \&$ path $\% 5 \mathrm{~B} \% 5 \mathrm{D}=378$

Guarinos, V. (ed.) (2013). Hombres en serie. Construcción de la masculinidad en los personajes de ficción seriada española de televisión. Madrid: Editorial Fragua.

Gubern, R. (1996). La agonía de los géneros. En Heredero, C. F. y Torreiro, C. (coords). Historia general del cine. Volumen X. Estados Unidos (1955-1975). América Latina. Madrid: Ediciones Cátedra.

Iglesias Simón, P. (2008). Del teatro al cine. Revista ADE-Teatro, $\mathrm{N}^{\mathrm{o}} 122$, pp. 126-145. Recuperado de http://www.pabloiglesiassimon.com/textos/Del_teatro_al_cine.pdf

Kazan, E. (1990). Elia Kazan. Mi vida. Memorias de un testigo excepcional de los tiempos dorados de Broadway y Hollywood. Madrid: Ediciones Temas de Hoy.

Loscertales, F. y Núñez, T. (2001). Violencia en las aulas. El cine como espejo social. Barcelona: Ediciones Octaedro.

Melero, A. (2014). La representación de la homosexualidad en el cine de la dictadura franquista. Zer, Vol. 19, No 36, pp. 189-204. Recuperado de http://www.ehu.eus/ojs/index.php/Zer/article/view/13500/12086

Mira Nouselles. A. (2011). Nuevas perspectivas, nuevas cartografías: de los Gay Studies a la teoría Queer. Secuencias. Revista de Historia del Cine, No 34, pp. 13-31. Recuperado de https://revistas.uam.es/secuencias/article/view/6324/6798

Pérez Rubio, P. (2004). El cine melodramático. Barcelona: Ediciones Paidós.

Pérez Rufí, J. P. (2016). Metodología de análisis del personaje cinematográfico: Una propuesta desde la narrativa fílmica. Razón y Palabra, Vol. 20, $\mathrm{N}^{\mathrm{O}}$ 4_95, pp. 534-552. Recuperado de http://www.revistarazonypalabra.org/index.php/ryp/article/view/68 $5 / \mathrm{pdf}$

Roberts, J. (2003). The Great American Playwrights on the Screen. A Critical Guide to Film, Video and DVD. New York: Applause. Theatre \& Cinema Books.

Sánchez Noriega, J. L. (2006). Veintinueve reflexiones sobre las adaptaciones literarias para uso de guionistas. En Huerta Floriano, M. A. y Sangro Colón, P. (Eds.) Guión de ficción en el cine. Planteamientos, nudo y desenlace. Salamanca: Publicaciones Universidad Pontificia de Salamanca.

Sánchez Noriega, J. L. (2000). De la literatura al cine. Teoría y análisis de la adaptación. Barcelona: Ediciones Paidós. Comunicación.

Torres, A. (1995). Vincente Minnelli. Madrid: Ediciones Cátedra.

Weingarten, L. (productor) \& Brooks, R. (director) (1958). La gata sobre el tejado de zinc [Cinta cinematográfica]. E.E.U.U: Metro Goldwyn Mayer. 
Williams, T. (2008). Memorias. Bacelona: Ediciones B para Bruguera.

Wyler, W. (productor y director) (1961). La calumnia [Cinta cinematográfica]. E.E.U.: United Artists.

Zurián Hernández, F. y Herrero Jiménez, B. (2014). Los estudios de género y la teoría fílmica feminista como marco teórico y metodológico para la investigación en cultura audiovisual. Área Abierta, Vol. 14, $\mathrm{N}^{\mathrm{o}} 3$, pp. 5-21. http://revistas.ucm.es/index.php/ARAB/article/view/46357/44209 